$15^{\text {th }}$ International Conference on

AEROSPACE SCIENCES \& AVIATION TECHNOLOGY,

$\boldsymbol{A S A T}$ - 15 - May 28 - 30, 2013, Email: asat@mtc.edu.eg,

Military Technical College, Kobry Elkobbah, Cairo, Egypt,

Tel: +(202) 24025292 -24036138, Fax: +(202) 22621908

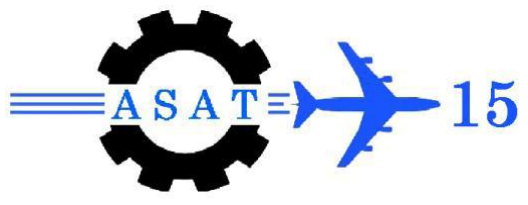

\title{
Comparison of Classical and Predictive Autopilot Design for Tactical Missile
}

\author{
M. S. Mohamed ${ }^{*}$, G. A. El-Sheikh ${ }^{\dagger}$, A. M. Bayoumy ${ }^{\dagger}$ and A. A. El-Ramlawy ${ }^{\S}$
}

\begin{abstract}
Because the missile is autonomous, its control system must provide adequate flight stability while ensuring sufficient response to track commands. This paper is devoted to investigate the usefulness of the classical and modern control techniques for autopilot design for different evaluation approaches. The present work is concerned with improving the performance of a surface-to-surface controlled aerodynamically guided missile system via both classical PID and predictive autopilots. The design and analysis necessitate somehow accurate system model with different uncertainties via 6-DOF simulation. The governing differential equations of the missile motion are derived with the aerodynamic model of the missile constructed by means of the Missile Datcom software. After obtaining the required aerodynamic stability derivatives using the generated aerodynamic data, the necessary transfer functions are determined based on the equations of the missile motion. Next, the normal acceleration autopilot is designed using the determined transfer functions. The autopilot is designed to realize the command signals generated by the guidance laws which are in the form of normal acceleration components. Using the entire system model, the computer simulations are carried out using the Matlab-Simulink software where the classical and predictive autopilots are compared via time response along the flight path.
\end{abstract}

Keywords: Classical control, gain scheduling, normal acceleration control, model-based predictive control.

\section{Nomenclature:}

\begin{tabular}{|c|c|c|c|}
\hline $\mathrm{A}, \mathrm{B}, \mathrm{C}$ & State-space matrices & $\mathrm{D}$ & Drag force, Missile diameter \\
\hline$a_{n}$ & Normal acceleration & $\mathrm{e}_{\mathrm{q}}$ & Error in pitch rate \\
\hline$a_{n c}$ & Commanded normal acceleration & $\mathrm{F}_{\mathrm{B}}$ & Resultant of external forces with \\
\hline B & $\begin{array}{l}\text { Transformation matrix from Earth } \\
\text { axes to body axes }\end{array}$ & & respect to body axes \\
\hline $\mathrm{C}_{\mathrm{D}}$ & Coefficient of drag & g & Gravitational acceleration \\
\hline $\mathrm{C}_{\mathrm{L}}$ & Coefficient of lift & $\mathrm{H}$ & Altitude \\
\hline $\mathrm{C}_{1}$ & Coefficient of rolling moment & $\mathrm{H}_{\mathrm{B}}$ & Angular momentum with respect \\
\hline $\mathrm{C}_{\mathrm{m}}$ & Coefficient of pitching moment & & to body axes \\
\hline & Coefficient of yawing moment & $\mathrm{I}_{\mathrm{xx}}, \mathrm{I}_{\mathrm{yy}}, \mathrm{I}_{\mathrm{zz}}$ & Moments of inertia about body axes \\
\hline $\mathrm{Cx}_{\mathrm{B}} \mathrm{y}_{\mathrm{B}} \mathrm{Z}_{\mathrm{B}}$ & Body axes & $\mathrm{I}_{\mathrm{xy}}, \mathrm{I}_{\mathrm{zy}}, \mathrm{I}_{\mathrm{xz}}$ & Product of moments of inertia \\
\hline $\mathrm{C}_{\mathrm{Y}}$ & Coefficient of side force & & about body axes \\
\hline
\end{tabular}

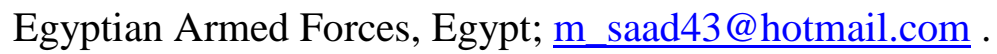

$\dagger \quad$ Prof., Pyramids Higher Institute for Engineering and Technology;

gaelsheikh@gmail.com.

\$ Egyptian Armed Forces, Egypt; ambayoumy@gmail.com .

$\S$ Egyptian Armed Forces, Egypt; abaset92@yahoo.com. 


\begin{tabular}{|c|c|c|c|}
\hline $\mathrm{i}_{\mathrm{B}}, \mathrm{j}_{\mathrm{B}}, \mathrm{k}_{\mathrm{B}}$ & Body axes unit vectors & $\mathrm{q}_{\mathrm{c}}$ & Commanded pitch rate \\
\hline $\mathrm{J}$ & Inertia tensor & $\mathrm{S}$ & Reference area \\
\hline $\mathrm{K}_{\mathrm{a}}$ & Normal acceleration gain & $\mathrm{s}$ & Laplace operator \\
\hline $\mathrm{K}_{\mathrm{q}}$ & Pitch rate gain & $\mathrm{T}_{\mathrm{s}}$ & Sampling time \\
\hline $\mathrm{k}$ & Sample number & $\mathrm{t}$ & Time \\
\hline $\mathrm{L}$ & Lift force, Rolling moment & $\mathrm{t}_{\mathrm{r}}$ & Rise time \\
\hline $\mathrm{L}_{\mathrm{p}}$ & Rolling moment due to roll rate & $\mathrm{t}_{\mathrm{s}}$ & Settling time \\
\hline $\mathrm{L}_{\xi}$ & $\begin{array}{l}\text { Rolling moment due to aileron } \\
\text { angle }\end{array}$ & $\begin{array}{l}\mathrm{u}, \mathrm{v}, \mathrm{w} \\
\mathrm{u}\end{array}$ & $\begin{array}{l}\text { Velocity component in body axes } \\
\text { Input signal }\end{array}$ \\
\hline $1_{\mathrm{p}}$ & $\begin{array}{l}\text { Position of accelerometer in front } \\
\text { of c.g. }\end{array}$ & $\begin{array}{l}\mathrm{u}_{0} \\
\mathrm{u}_{\eta}\end{array}$ & $\begin{array}{l}\text { Undisturbed longitudinal velocity } \\
\text { Control signal }\end{array}$ \\
\hline M & $\begin{array}{l}\text { Pitching moment, Resultant of } \\
\text { external moments w.r.t. body axes }\end{array}$ & $\begin{array}{l}\mathrm{V} \\
\mathrm{v}_{\mathrm{B}}\end{array}$ & $\begin{array}{l}\text { Total velocity } \\
\text { Velocity w.r.t. body frame }\end{array}$ \\
\hline $\begin{array}{l}\text { M. O. } \\
\text { Ma }\end{array}$ & $\begin{array}{l}\text { Maximum percentage overshoot } \\
\text { Mach number }\end{array}$ & $\mathrm{X}_{\mathrm{u}}$ & $\begin{array}{l}\text { Axial force due to longitudinal } \\
\text { Velocity }\end{array}$ \\
\hline & $\begin{array}{l}\text { Pitching moment due to pitch rate } \\
\text { Pitching moment due to vertical }\end{array}$ & $\mathrm{x}, \mathrm{y}, \mathrm{z}$ & $\begin{array}{l}\text { Position of body c.g. w.r.t. Earth } \\
\text { Axes }\end{array}$ \\
\hline & Velocity & $\mathrm{Y}$ & Side force \\
\hline $\mathrm{M}_{\alpha}$ & $\begin{array}{l}\text { Pitching moment due to angle of } \\
\text { attack }\end{array}$ & $\begin{array}{l}Y_{\mathrm{r}} \\
Y_{\mathrm{v}}\end{array}$ & $\begin{array}{l}\text { Side force due to yaw rate } \\
\text { Side force due to side velocity }\end{array}$ \\
\hline $\mathrm{M}_{\eta}$ & $\begin{array}{l}\text { Pitching moment due to elevator } \\
\text { angle }\end{array}$ & $\begin{array}{l}Y_{\zeta} \\
y\end{array}$ & $\begin{array}{l}\text { Side force due to rudder angle } \\
\text { Output vector }\end{array}$ \\
\hline $\mathrm{m}$ & Missile mass & $\mathrm{Z}_{\mathrm{q}}$ & Normal force due to pitch rate \\
\hline $\mathrm{N}$ & Yawing moment & $\mathrm{Z}_{\mathrm{w}}$ & Normal force due to vertical \\
\hline $\mathrm{N}_{2}$ & Prediction horizon & & velocity \\
\hline $\mathrm{N}_{\mathrm{r}}$ & Yawing moment due to yaw rate & $\mathrm{Z}_{\alpha}$ & Normal force due to angle of attack \\
\hline $\mathrm{N}_{\mathrm{u}}$ & Control horizon & $\mathrm{Z}_{\eta}$ & Normal force due to elevator angle \\
\hline $\mathrm{N}_{\mathrm{v}}$ & $\begin{array}{l}\text { Yawing moment due to side } \\
\text { velocity }\end{array}$ & $\begin{array}{l}\alpha \\
\beta\end{array}$ & $\begin{array}{l}\text { Angle of attack } \\
\text { Side slip angle }\end{array}$ \\
\hline $\mathrm{N}_{\zeta}$ & $\begin{array}{l}\text { Yawing moment due to rudder } \\
\text { angle }\end{array}$ & $\zeta_{\mathrm{sp}}$ & $\begin{array}{l}\text { Rudder angle } \\
\text { Short period mode damping ratio }\end{array}$ \\
\hline $\mathrm{P}$ & Position vector & $\eta$ & Elevator angle \\
\hline $\mathrm{p}, \mathrm{q}, \mathrm{r}$ & Roll, pitch and yaw rates & $\theta$ & Pitch angle \\
\hline Q & Dynamic pressure & $\xi$ & Aileron angle \\
\hline
\end{tabular}

\section{Introduction}

An autopilot is a closed-loop flight control system. It is a minor loop inside the main guidance loop. A missile will maneuver up-down or left-right in an apparently satisfactory manner if a control surface is moved or the direction of thrust is altered [1]. The missile carries accelerometers and/or gyros to provide additional feedback into the missile servos to modify the missile motion. The missile control system consisting of servos, control surfaces or thrust vector elements, the airframe and feedback instruments plus the control electronics which is usually called an autopilot.

The function of the autopilot subsystem can be defined as follows:

- Provide the required missile normal acceleration response characteristics.

- Stabilize or damp the airframe.

- Reduce the missile performance sensitivity to disturbance inputs over the missile's flight envelope. 
Autopilots are commonly classified as either controlling the motion in the pitch and yaw planes in which case they are called lateral autopilots, or they control the motion about the fore and aft axis in which case they are called roll autopilots [1].

The goal of this paper is a comparison of two autopilot designs for a surface-to-surface highperformance tactical missile. One design is obtained using the gain scheduled classical control techniques and the other design is based on model based predictive control. The PID controller is scheduled as a function of flight conditions employing a good technique along trajectory whereas the predictive one will utilize single model to control normal acceleration along trajectory. Simulation is created for the whole system as a closed-loop system to verify the performance of the designed systems.

\section{Missile Model}

\section{Equations of Motion}

The equations of motion are derived by applying Newton's laws of motion, which relate the summation of the external forces and moments to the linear and angular accelerations of the system or body [2]. To make this application, certain assumptions must be made and an axis system defined as shown in Fig. 1 [1].

- The center of the body axis system is located at the center of gravity of the missile and the axis system is fixed to the airframe and rotates with it and axis $\mathrm{x}_{\mathrm{B}}$ is directed along vehicle longitudinal axis and $\mathrm{z}_{\mathrm{B}}$ is directed downward.

- $\quad \mathrm{x}_{\mathrm{B}} \mathrm{y}_{\mathrm{B}}$ plane and $\mathrm{x}_{\mathrm{B}} \mathrm{z}_{\mathrm{B}}$ plane are planes of symmetry then the mixed products of inertia $\mathrm{I}_{\mathrm{xy}}, \mathrm{I}_{\mathrm{xz}}$ and $\mathrm{I}_{\mathrm{yz}}$ are equal to zero.

- The thrust vector is directed to the $\mathrm{x}_{\mathrm{B}}$-axis and there is no offset between them.

- The mass and moments of inertia of the missile remains constant as the amount of propellant consumed during selected integration step in the powered region of the vehicle flight may be safely neglected.

- The missile is a rigid body.

- The Earth is an inertial reference, and the atmosphere is fixed with respect to the Earth.

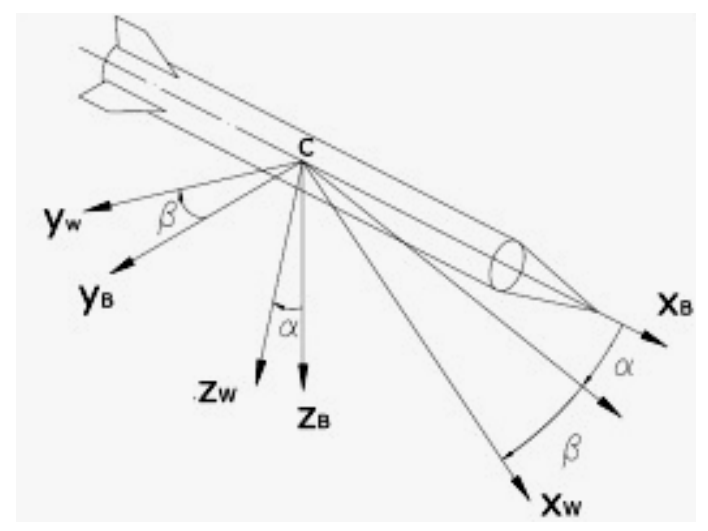

Fig. 1. Missile configuration and reference frames

From Newton's second law of motion,

Force Equation:

$$
\sum F=\frac{d}{d t}\left(m v_{B}\right)
$$


Moment Equation:

$$
F_{B}+B m g=\frac{d}{d t}\left(m v_{B}\right)=m \frac{d}{d t}\left(v_{B}\right)
$$

$$
\begin{gathered}
\sum M=\frac{d H_{B}}{d t} \\
\sum M=\frac{d}{d t}\left(J \omega_{B}\right)=J \frac{d}{d t}\left(\omega_{B}\right)+\omega_{B} \times J \omega_{B}
\end{gathered}
$$

Then, the force equation will be:

And the moment equation will be:

$$
\dot{v}_{B}=\frac{1}{m} F_{B}-\omega_{B} \times J v_{B}+B g
$$

$$
\dot{\omega}_{B}=J^{-1} F_{B}-J^{-1} \omega_{B} \times J \omega_{B}
$$

where $\omega_{B}=p \vec{\imath}_{B}+q \vec{\jmath}_{B}+r \vec{k}_{B}$ and $v_{B}=u \vec{\imath}_{B}+v \vec{\jmath}_{B}+w \vec{k}_{B}$

And let $\varphi, \theta, \psi$ be the roll, pitch and yaw angles respectively. Hence, Euler angles $\varphi, \theta, \psi$ can be expressed from the attitude equation:

$$
\left[\begin{array}{c}
\dot{\varphi} \\
\dot{\theta} \\
\dot{\psi}
\end{array}\right]=\left[\begin{array}{ccc}
1 & \tan \theta \sin \varphi & \tan \theta \cos \varphi \\
0 & \cos \varphi & -\sin \varphi \\
0 & \frac{\sin \varphi}{\cos \theta} & \frac{\cos \varphi}{\cos \theta}
\end{array}\right]\left[\begin{array}{l}
p \\
q \\
r
\end{array}\right]
$$

And the navigation equation will be:

where: $P=x \vec{\imath}+y \vec{\jmath}+z \vec{k}$

$$
\dot{P}=B^{T} v_{B}
$$

Finally, equations (5), (6), (7) and (8) are the equations of motion in state space form [2].

\section{Coefficients Calculation}

Forces and moments acting on the missile is resulted from the aerodynamic forces (Lift and Drag) and the thrust force [2].

Aerodynamic forces:

- Lift: $L=C_{L}\left(1 / 2 * \rho * V^{2} * S\right)$

- Drag: $\mathrm{D}=\mathrm{C}_{\mathrm{D}}\left(1 / 2 * \rho^{*} \mathrm{~V}^{2} * \mathrm{~S}\right)$

- Side force: $Y=C_{Y}\left(1 / 2 * \rho * V^{2 * S}\right)$

Aerodynamic moments:

- Pitching moment: $\mathrm{M}=\mathrm{C}_{\mathrm{m}}\left(1 / 2 * \rho * \mathrm{~V}^{2} * \mathrm{~S} * \mathrm{D}\right)$

- Yawing moment: $N=C_{n}\left(1 / 2 * \rho * V^{2} * S * D\right)$

- Rolling moment: $\mathrm{L}=\mathrm{C}_{1}\left(1 / 2 * \rho^{*} \mathrm{~V}^{2 *} \mathrm{~S} * \mathrm{D}\right)$

The coefficients of forces and moments will be calculated using the software of Missile DATCOM at various deflection of fins and at various flight conditions (Mach, angle of attack and side slip angle) [3]. The various aerodynamic coefficients are primarily dependent on the aerodynamic angles $\alpha$ and $\beta$ and less dependent on a number of other variables. The coefficient of drag is dependent on the angle of attack $\alpha$, Ma and $\mathrm{H}$ since the skin friction drag is dependent on Reynolds number. The other coefficients depend on the angle of attack $\alpha$, sideslip angle $\beta$ and Ma. 


\section{Linearization of Missile Model}

The linear equations needed for control system design will be derived using the small perturbation method from the nonlinear model. In [4], a complete linearization for force and moment equations (5) and (6) in the state model is presented for both the application of the PID time-domain and frequency domain techniques. The six equations of motion can be written as:

$$
\left[\begin{array}{c}
\Delta \dot{u} \\
\Delta \dot{v} \\
\Delta \dot{w} \\
\Delta \dot{p} \\
\Delta \dot{q} \\
\Delta \dot{r}
\end{array}\right]=\left[\begin{array}{cccccc}
X_{u} & 0 & 0 & 0 & 0 & 0 \\
0 & Y_{v} & 0 & 0 & 0 & \left(Y_{r}-u_{0}\right) \\
0 & 0 & Z_{w} & 0 & \left(u_{0}+Z_{q}\right) & 0 \\
0 & 0 & 0 & L_{p} & 0 & 0 \\
0 & 0 & M_{w} & 0 & M_{q} & 0 \\
0 & N_{v} & 0 & 0 & 0 & N_{r}
\end{array}\right]\left[\begin{array}{c}
u \\
v \\
w \\
p \\
q \\
r
\end{array}\right]+\left[\begin{array}{ccc}
0 & 0 & 0 \\
0 & 0 & Y_{\zeta} \\
0 & Z_{\eta} & 0 \\
L_{\xi} & 0 & 0 \\
0 & M_{\eta} & 0 \\
0 & 0 & N_{\zeta}
\end{array}\right]\left[\begin{array}{l}
\xi \\
\eta \\
\zeta
\end{array}\right]
$$

\section{Classical PID Control System Design}

\section{Design Goals and Requirements}

The task of the control system is to produce the necessary normal force and maneuver the missile (change the direction of the missile velocity vector) quickly and efficiently as a result of guidance signals [1]. Considering first-order lag actuator of transfer function $(60 /(s+60))$ and unity gain rate-gyro and accelerometer (as the dynamic characteristics of rate-gyro and accelerometer is very high with respect to missile dynamics), the state-space of pitch autopilot yields:

$$
\begin{gathered}
{\left[\begin{array}{c}
\dot{\alpha} \\
\dot{q} \\
\dot{\eta}
\end{array}\right]=\left[\begin{array}{ccc}
Z_{w} & 1+\frac{Z_{q}}{u_{0}} & \frac{Z_{\eta}}{u_{0}} \\
M_{\alpha} & M_{q} & M_{\eta} \\
0 & 0 & -60
\end{array}\right]\left[\begin{array}{l}
\alpha \\
q \\
\eta
\end{array}\right]+\left[\begin{array}{c}
0 \\
0 \\
60
\end{array}\right] u_{\eta}} \\
{\left[\begin{array}{c}
a_{n} \\
q
\end{array}\right]=\left[\begin{array}{ccc}
l_{p} M_{\alpha}-Z_{\alpha} & l_{p} M_{q}-Z_{q} & l_{p} M_{\eta}-Z_{\eta} \\
0 & 1 & 0
\end{array}\right]\left[\begin{array}{c}
\alpha \\
q \\
\eta
\end{array}\right]}
\end{gathered}
$$

\section{Choice of Trim Conditions}

In order to select the design points, the Mach number and altitude must be plotted with the flight time, or instead of them the dynamic pressure can be introduced with the change of flight time as shown in Fig. 2.

The design points must be at different dynamic pressure during the powered phase (which is from 0 to $13 \mathrm{sec}$ ) and unpowered phase (from $13 \mathrm{sec}$ till flight end) in order to avoid repeating of design points or introducing large number of design points. Due to rapid change in dynamic pressure and missile states during the powered phase, a point is selected at every 5 sec. Due to moderate change in dynamic pressure and missile parameters during the unpowered phase, it is divided into regions with mid and final-points for each region are selected. Then the set of designing points are shown in Table 1 and Fig. 2.

Table 1 Set of designing points

\begin{tabular}{l|l|l|l|l|l|l|l|l|l}
\hline \hline Point & 1 & 2 & 3 & 4 & 5 & 6 & 7 & 8 & 9 \\
\hline Time [sec] & 1 & 5 & 10 & 13 & 20 & 40 & 90 & 150 & 180 \\
\hline \hline
\end{tabular}




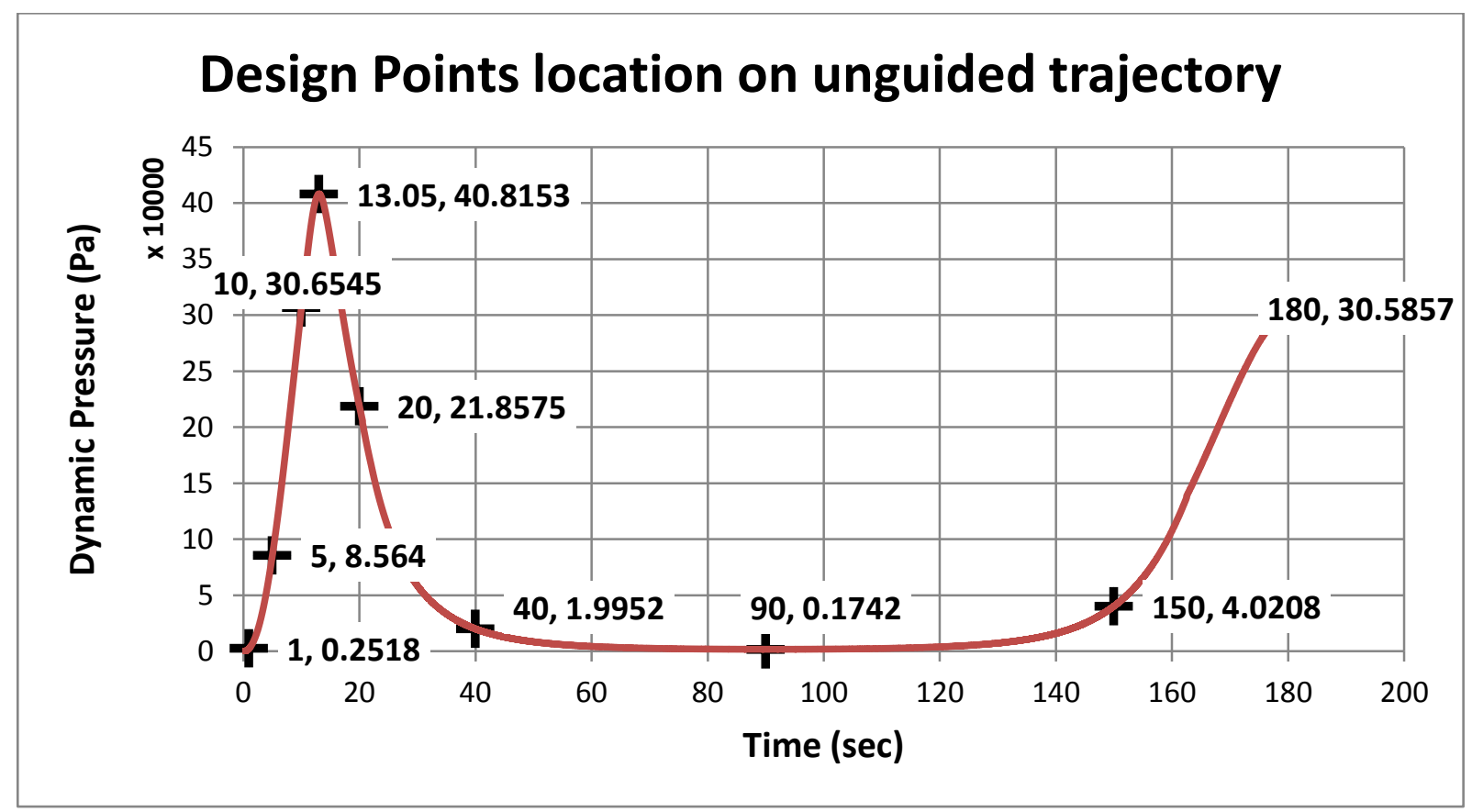

Fig. 2. Change of dynamic pressure during flight time

It is necessary to select a point at which the autopilot design is carried out and to generalize the structure of the controller for the other points. This point needed to be of moderate coefficients to be near to higher dynamic pressure point and lower dynamic parameters point or in between of them. From Fig. 2, it will be acceptable if choosing point at time $(\mathrm{t}=5 \mathrm{sec})$ to be the nominal design point which has the state-space model:

$$
\begin{gathered}
{\left[\begin{array}{c}
\dot{\alpha} \\
\dot{q} \\
\dot{\eta}
\end{array}\right]=\left[\begin{array}{ccc}
-0.2253 & 0.9977 & -0.00218 \\
-20.9856 & -0.4221 & -0.47785 \\
0 & 0 & -60
\end{array}\right]\left[\begin{array}{l}
\alpha \\
q \\
\eta
\end{array}\right]+\left[\begin{array}{c}
0 \\
0 \\
60
\end{array}\right] u_{\eta}} \\
{\left[\begin{array}{c}
a_{n} \\
q
\end{array}\right]=\left[\begin{array}{ccc}
8.896 & 0.0893 & 0.086 \\
0 & 1 & 0
\end{array}\right]\left[\begin{array}{l}
\alpha \\
q \\
\eta
\end{array}\right]}
\end{gathered}
$$

\section{Normal Acceleration Autopilot Design}

The autopilot is designed to control the normal acceleration, which its input is a desired normal acceleration $\left(\mathrm{a}_{\mathrm{nc}}[\mathrm{g}]\right)$ command sent from the guidance-loop. The complete normal acceleration control system block diagram is shown in Fig. 3, where the inner loop is the pitch damper system to ensure adequate damping ratio.

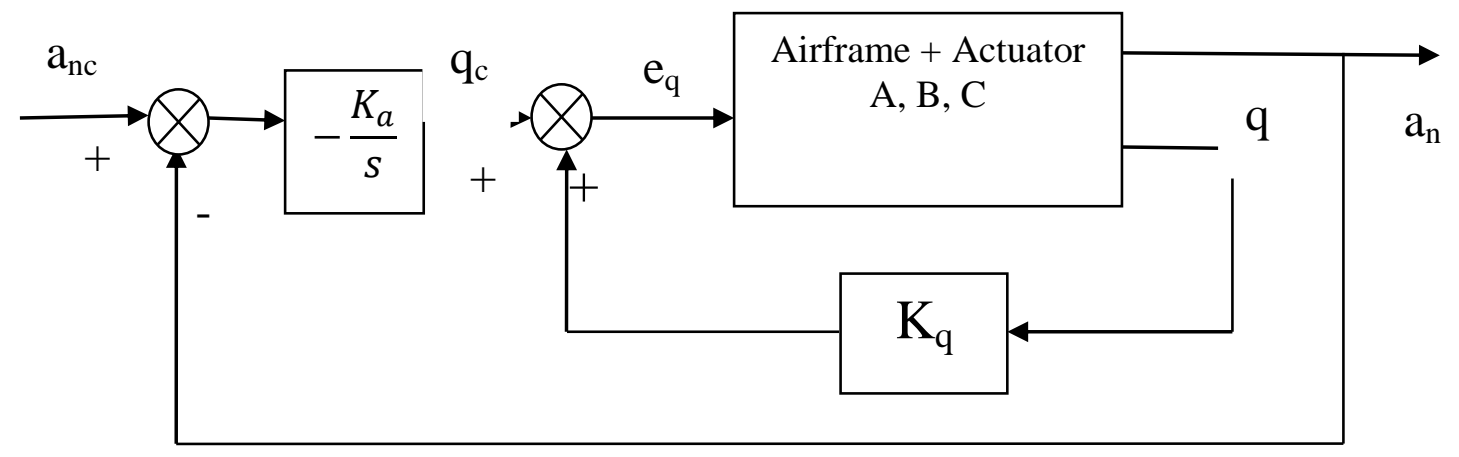

Fig. 3. Normal acceleration control system block diagram 
The two short period complex poles $(-0.3237 \pm 4.575 \mathrm{i})$ have low damping ( $\zeta \mathrm{sp}=0.0705)$ and move on the imaginary axis due to increase of $\mathrm{K}_{\mathrm{q}}$ and then intersecting on the real axis, one of them moves to the short period zero $(-0.13)$ and the other pole intersects with actuator pole $(-60)$ and moves on the imaginary axis towards infinity. By increasing the value of $\mathrm{K}_{\mathrm{q}}$, the damping ratio of the short period mode increases about 0.7 where the value of $\mathrm{K}_{\mathrm{q}}=11.8$ at $\left(\zeta_{\mathrm{sp}}=0.706\right)$ Fig. $4[5]$.

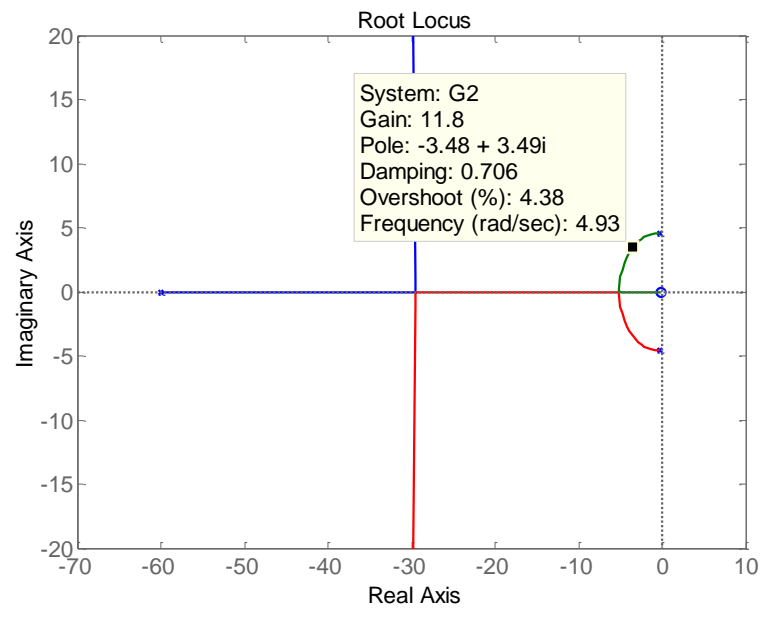

Fig. 4. Root locus of pitch damper loop

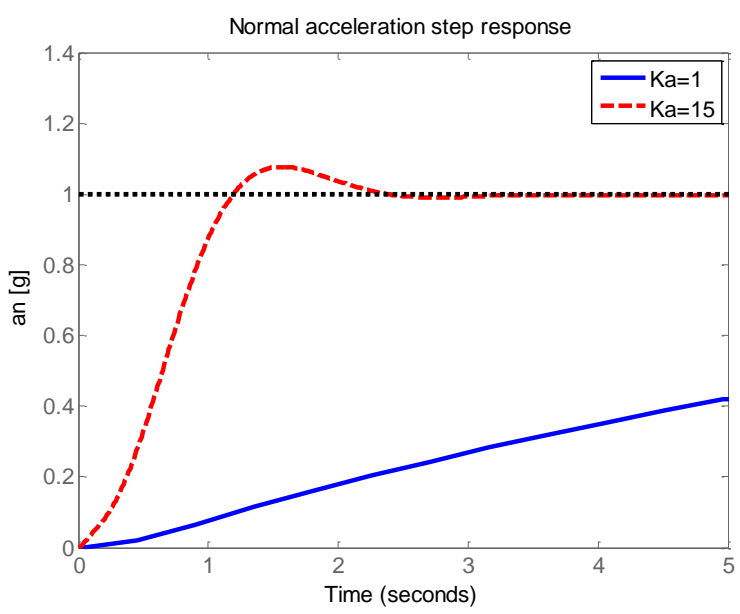

Fig. 5. Normal acceleration step response

Using $\mathrm{K}_{\mathrm{a}}=1$, the dynamic characteristics are shown in Table 2 . The value of $\mathrm{Ka}$ is increased and the characteristics are calculated till acceptable requirements reached at $\mathrm{K}_{\mathrm{a}}=15$ which are shown in Table 2 and shown in Fig. 5.

Table 2 Performance characteristics

\begin{tabular}{c|c|c|c|c|c|c}
\hline \hline $\mathrm{K}_{\mathrm{a}}$ & $\mathrm{GM}[\mathrm{dB}]$ & $\mathrm{PM}\left[{ }^{\circ}\right]$ & $\omega_{\mathrm{gc}}[\mathrm{rad} / \mathrm{sec}]$ & $\mathrm{t}_{\mathrm{r}}[\mathrm{sec}]$ & $\mathrm{t}_{\mathrm{s}}[\mathrm{sec}]$ & M.O. [\%] \\
\hline 1 & 38.9 & 88.1 & 0.112 & 26.1 & 34.2 & 0 \\
\hline 15 & 15.4 & 61.8 & 1.62 & 1.1 & 2.11 & 8 \\
\hline \hline
\end{tabular}

\section{Gain scheduling}

The nominal mathematical model, used in designing the control laws, only approximates the behavior of the physical missile, and even then at specific flight points only. Gain scheduling of $\mathrm{K}_{\mathrm{q}}$ and $\mathrm{K}_{\mathrm{a}}$ with dynamic pressure is accepted as being appropriate for good responses across the whole flight trajectory and to ensure acceptable system robustness. The methodology of this method is to keep the controller with its parameters and adjust the gain multiplied by the controller $\left(\mathrm{K}_{\mathrm{a}}, \mathrm{K}_{\mathrm{q}}\right)$ in both the inner and outer loops and then scheduling the gain with the flight conditions. The scheduling is shown in Table 3.

\section{Predictive Control System Design}

\section{Introduction}

Model Based Predictive Control (MPC) is a control methodology which uses on-line process model for calculating predictions of the future plant output and for optimizing future control actions. In fact MPC is not a single specific control strategy but rather a family of control methods which have been developed with certain ideas in common. According to Fig. 6, the future outputs for a determined horizon $\mathrm{N}$, called the prediction horizon, are predicted at each instant $t$ using the process model as shown in Eqn (2). 
Table $3 K_{q}$ and $K_{a}$ scheduling

\begin{tabular}{c|c|c|c|c|c|c|c|c}
\hline \hline Time & 5 & 10 & 13 & 20 & 40 & 90 & 150 & 180 \\
\hline $\mathrm{Q}[\mathrm{Pa}]$ & 85640 & 306545 & 408153 & 218575 & 19952 & 1742 & 40208 & 305857 \\
\hline $\mathrm{Kq}$ & 11.8 & 5.09 & 3.75 & 5.23 & 22.3 & 86 & 15.7 & 5.53 \\
\hline $\mathrm{Ka}$ & 15 & 1.1 & 0.43 & 0.57 & 4.25 & 27.5 & 3.1 & 2.4 \\
\hline \hline
\end{tabular}

$y(k+i \mid k)=C_{d} A_{d}{ }^{i} X(k)+\sum_{j=0}^{i-1} C_{d}\left(A_{d}{ }^{j} B_{d} u(k-1)+\left(\sum_{h=0}^{i-j-1} A_{d}{ }^{h} B_{d}\right) \Delta u(k+j)\right)$

Then the set of future control signals is calculated by optimizing a determined criterion in order to keep the process as close as possible to the reference trajectory $a_{n c}(t+k)$. Finally, The control signal $u(t \mid$ $\mathrm{t})$ is sent to the process whilst the next control signals calculated are rejected, because at the next sampling instant $\mathrm{y}(\mathrm{t}+$ 1) is already known and repeating with this new value and all the sequences are brought up to date.

MPC is a digital control strategy. It uses a discrete linear model of the plant as a predictor of its future behavior. The

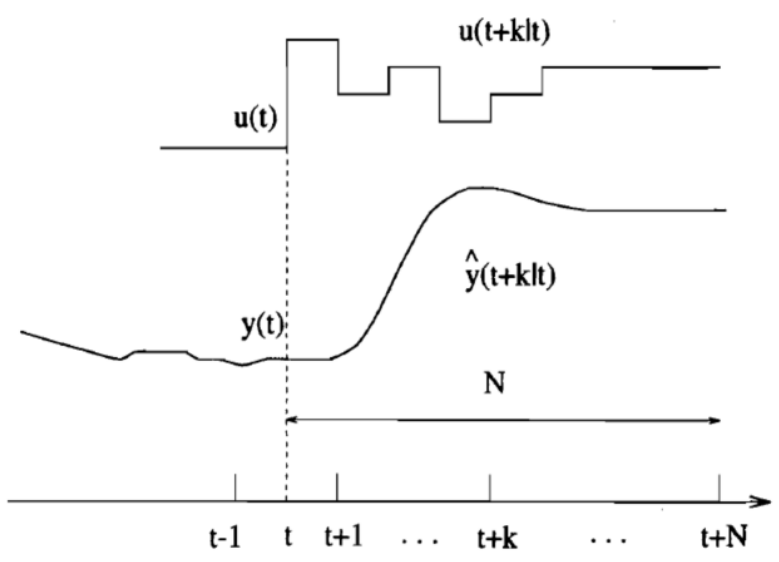

Fig. 6 MPC strategy control sequence applied to the plant is the optimum calculated sequence that provides minimum value for the objective function $\mathbf{J}$ as shown in Eqn (3).

$$
J=\min \left\{\sum_{i=0}^{p-1}\left(\sum_{j=N_{1}}^{N_{2}}\left|w_{i+1, j}^{y}\left(y_{j}(k+i+1 \mid k)-r_{j}(k+i+1)\right)\right|^{2}+\sum_{j=1}^{N_{u}}\left|w_{i, j}^{\square} \square u_{j}(k+i \mid k)\right|^{2}+\sum_{j=1}^{N_{u}}\left|w_{i, j}^{u}\left(u_{j}(k+i \mid k)-\bar{u}_{j}\right)\right|^{2}\right)\right\}
$$

$\mathrm{w}_{\mathrm{i}, \mathrm{j}}^{\mathrm{u}}, \mathrm{w}_{\mathrm{i}, \mathrm{j}} \mathrm{u}, \mathrm{w}_{\mathrm{i}, \mathrm{j}}^{\mathrm{y}}$ are nonnegative weights for the input, input rate and output respectively. Normally, the objective is chosen to be a combination of output tracking error and control energy. This optimization could be constrained either by input or output constraints[6].

\section{Model Discretization}

According to the Shannon sampling theorem [7], in order to select the suitable sampling time, it is necessary to realize the maximum natural frequency of the vehicle [7]. The maximum natural frequency appears in the pitch transfer function when the vehicle approaches target which is

Maximum natural frequency:

$$
\omega_{\mathrm{n}}=5.847[\mathrm{rad} / \mathrm{s}]
$$

The sampling time will be:

$$
\begin{aligned}
& T_{s} \leq \frac{\pi}{\omega_{n}}=0.5735[\mathrm{sec}] \\
& \stackrel{\text { yields }}{\longrightarrow} T_{s}=0.01[\mathrm{sec}]
\end{aligned}
$$


Although classical control needs nine design points to maintain its stability, it was found that MPC could maintain the same stability (or even better) with a single design point chosen at the high dynamic pressure point especially at $(\mathrm{t}=180 \mathrm{sec})$.

Discretization of the state-space model [7] of this point using sampling time $\left(\mathrm{T}_{\mathrm{s}}=0.01 \mathrm{sec}\right)$ yields to:

$$
\begin{aligned}
{\left[\begin{array}{l}
\alpha \\
q \\
\eta
\end{array}\right](k+1)=} & {\left[\begin{array}{ccc}
0.9937 & 0.009912 & -7.805 \times 10^{-5} \\
-0.3369 & 0.9908 & -0.009335 \\
0 & 0 & 0.5488
\end{array}\right]\left[\begin{array}{l}
\alpha \\
q \\
\eta
\end{array}\right](k) } \\
& +\left[\begin{array}{c}
-1.961 \times 10^{-5} \\
-0.003085 \\
0.4512
\end{array}\right] u_{\eta}(k) \\
{\left[\begin{array}{c}
q \\
a_{n}
\end{array}\right](k)=} & {\left[\begin{array}{ccc}
0 & 1 & 0 \\
26.26 & -0.002858 & -0.006937
\end{array}\right]\left[\begin{array}{l}
\alpha \\
q \\
\eta
\end{array}\right](k) }
\end{aligned}
$$

\section{Normal Acceleration MPC Design}

The model predictive controller parameters are listed in Table 4.

Table 4 MPC parameters

\begin{tabular}{c|c|c|c|c|c|c}
\hline \hline \multicolumn{2}{c|}{ Horizon } & \multicolumn{3}{c|}{ Constraints } & \multicolumn{2}{c}{ Simulation scenario } \\
\hline $\mathrm{N}_{\mathrm{u}}$ & $\mathrm{N}_{2}$ & $\begin{array}{c}\text { Fin } \\
\text { deflection }\end{array}$ & $\mathrm{a}_{\mathrm{n}}[\mathrm{g}]$ & $\mathrm{q}[\mathrm{rad} / \mathrm{sec}]$ & $\mathrm{a}_{\mathrm{n}}$ & $\mathrm{q}$ \\
\hline 2 & 12 & $\mathbf{- 1 0} \leq \mathbf{u}_{\mathrm{n}} \leq \mathbf{1 0}$ & $\mathbf{- 1 0} \leq \mathbf{a}_{\mathbf{n}} \leq \mathbf{1 0}$ & $\mathbf{- 1 . 0 4} \leq \mathbf{q} \leq \mathbf{1 . 0 4}$ & step function & pulse function \\
\hline \hline
\end{tabular}

All the unmeasured disturbances in the input and outputs are neglected. The two outputs are considered measured and fed-back to the controller. MPC minimizes an objective function that contains output tracking error and input control energy. For MIMO system relative weights could be assigned for input and outputs. Table 5 shows different controller time

\begin{tabular}{|c|c|c|c|c|c|c|c|}
\hline \multirow{2}{*}{ Case } & \multicolumn{2}{|c|}{ Input weight } & \multicolumn{2}{|c|}{ Output weight } & \multirow{2}{*}{$\mathrm{t}_{\mathrm{r}}[\mathrm{sec}]$} & \multirow{2}{*}{$\begin{array}{c}\mathrm{t}_{\mathrm{s}} \\
{[\mathrm{sec}]}\end{array}$} & \multirow{2}{*}{ M.O. \% } \\
\hline & Weight & Rate & $a_{n}$ & $q$ & & & \\
\hline 1 & 0 & 0.1 & 1 & 1 & 0.53 & 1.6 & 3 \\
\hline 2 & 0.1 & 0.1 & 1 & 1 & $>20$ & $>20$ & 0 \\
\hline 3 & 0 & 1 & 1 & 1 & 0.64 & $>20$ & 11 \\
\hline 4 & 0 & 0.1 & 5 & 1 & 0.36 & 3.04 & 6 \\
\hline 5 & 0 & 0.1 & 1 & 5 & $>20$ & $>20$ & 0 \\
\hline 6 & 0 & 0.1 & 5 & 5 & 0.53 & 1.47 & 4 \\
\hline 7 & 0 & 0.1 & 0.1 & 0.1 & 0.64 & $>20$ & 11 \\
\hline
\end{tabular}
response for different input and outputs weights.

Table 5 Change of time characteristics with the weights

The response of normal acceleration at different weights is shown in Fig. 7. From this figure, one can choose the best results associated with the following weights (Table 6).

Table 6 Weights

\begin{tabular}{c|c|c|c}
\hline \hline \multicolumn{2}{c|}{ Input weight } & \multicolumn{2}{c}{ Output weight } \\
\hline Weight & Rate & $\mathrm{a}_{\mathrm{n}}$ & $\mathrm{q}$ \\
\hline 0 & 0.1 & 1 & 1 \\
\hline \hline
\end{tabular}



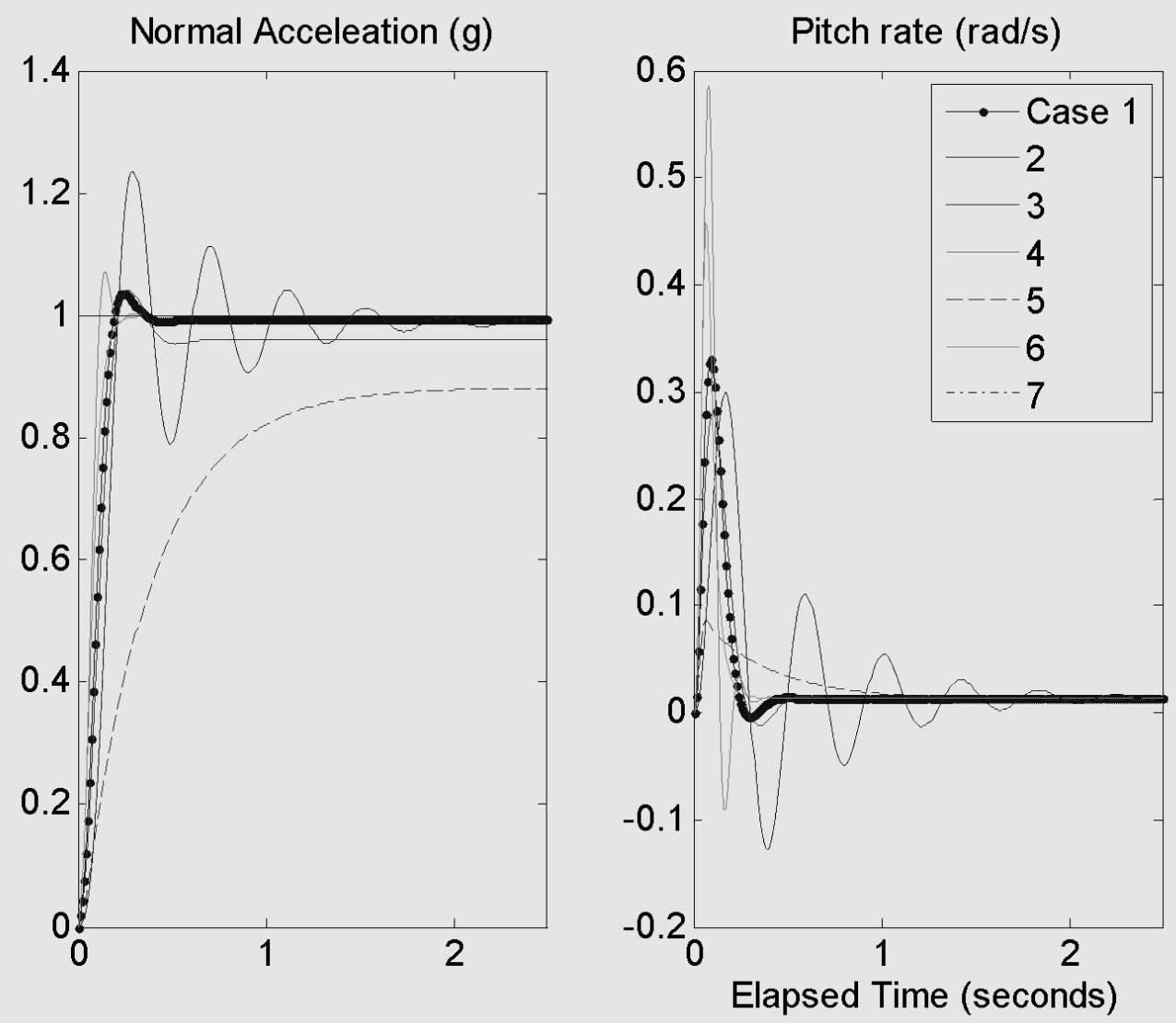

Fig. 7. Response of normal acceleration at selected weights

\section{Results of Normal Acceleration Autopilot Design}

Fig. 8 shows the block diagram of the simulation of autopilots with non-linear missile model shown in equations (1-8). Constructing the simulation as shown in [8] and performing it as presented in [9]. The results are shown in Fig. 9.

Controller of the normal acceleration is implemented using both classical and predictive control strategies for the whole flight trajectory. Cross wind is assumed to deviate the missile during its flight (Fig. 9a). Sensor noise is assumed to be a white noise with \pm 0.014 as shown in (Fig. 9b). Some model states, input and outputs, are shown in (Fig. 9c - f). the 3D trajectory of the whole flight is shown in (Fig. 9g). All plots are drawn for both classical and MPC controllers.

Remarks on the results:

- Fig. 9a, b show the wind model (acting from $5 \mathrm{sec}$. to $15 \mathrm{sec}$.) used with the noise model of bounds \pm 0.014 and zero mean value and variance $\left(6.54 \times 10^{-5}\right)$ and acting during the flight time.

- MPC is more robust than classical controller in the following aspects:

- Conducting both controllers, the response characteristics are shown in Table 7.

- MPC maintains the value of angle of attack and reducing its fluctuation (Fig. 9c).

- MPC reduces the deviation of elevator angle values from zero and reduces the load affecting control actuators (Fig. 9d).

- MPC tracks the commanded zero normal acceleration and pitch rate values with less overshoot (Fig. 9e, f). 
- The summit reached by the missile using MPC is less than the classical controller which minimizes flight time and increase range (Fig. 9g and Table 8).

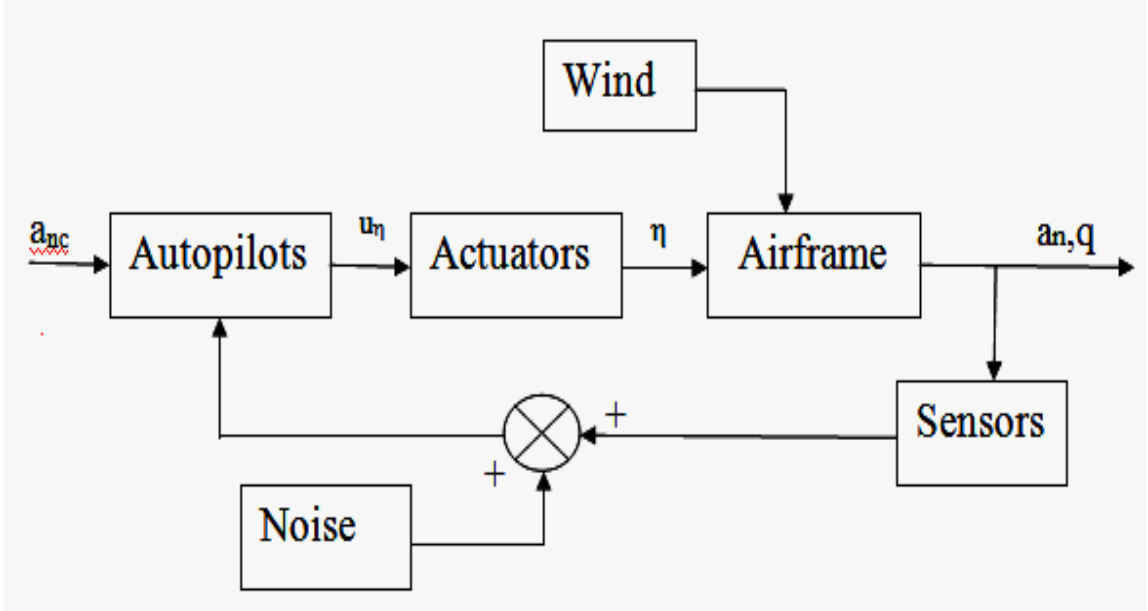

Fig. 8. Block diagram of the vehicle

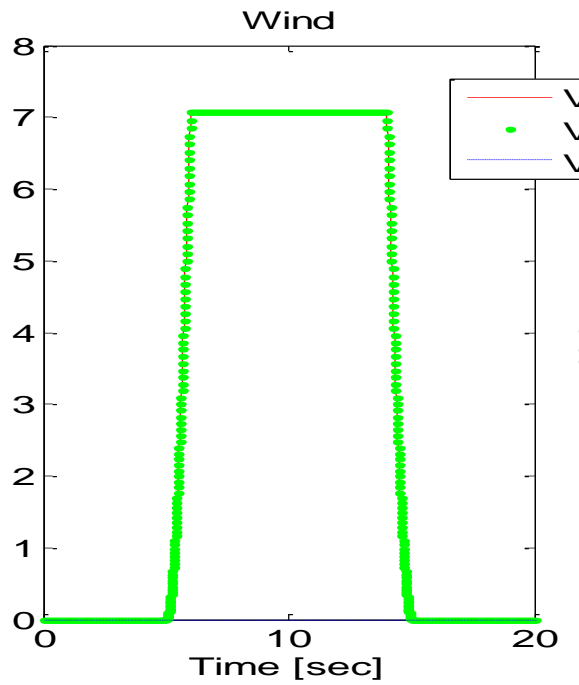

(a)

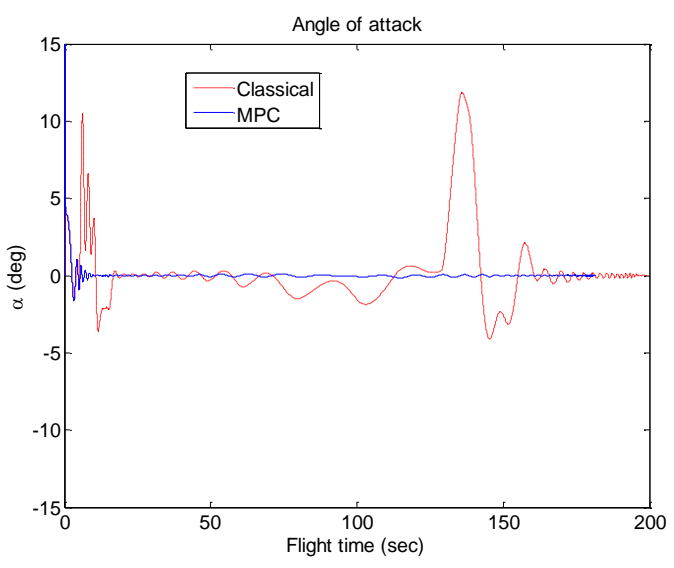

(c)

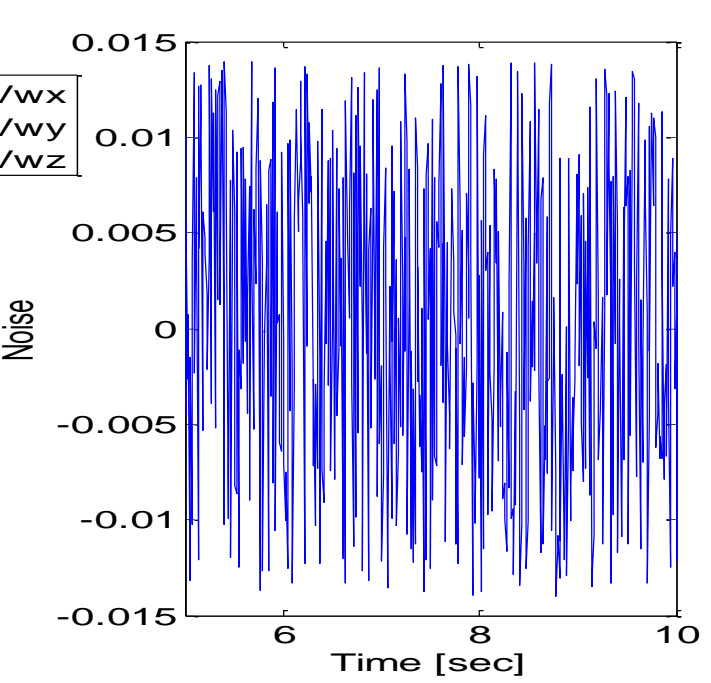

(b)

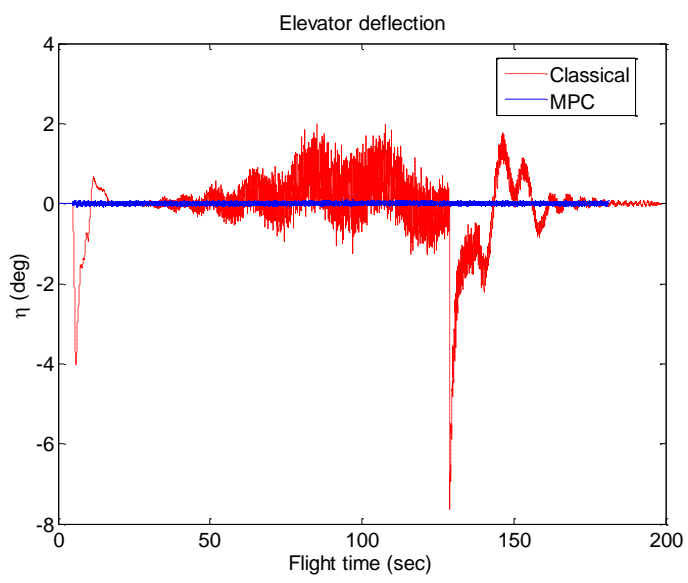

(d)

Fig. 9 Simulation results 


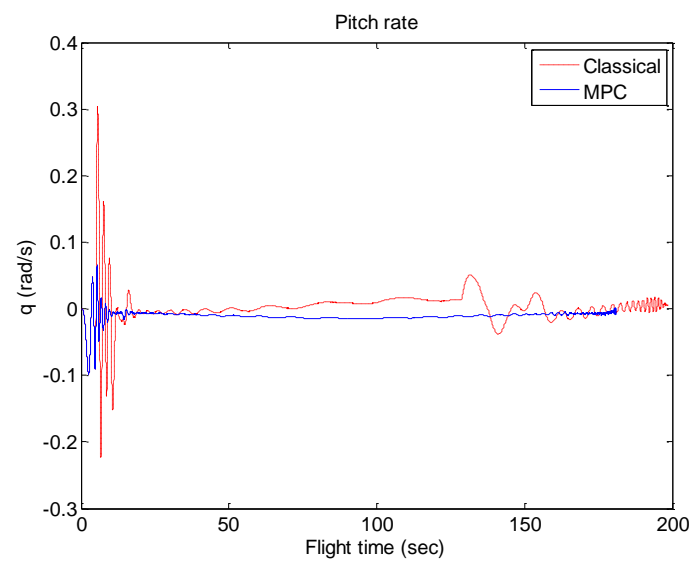

(e)

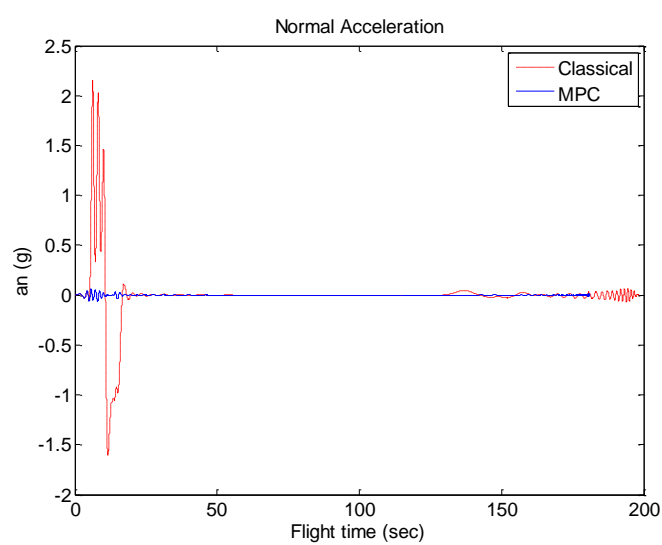

(f)

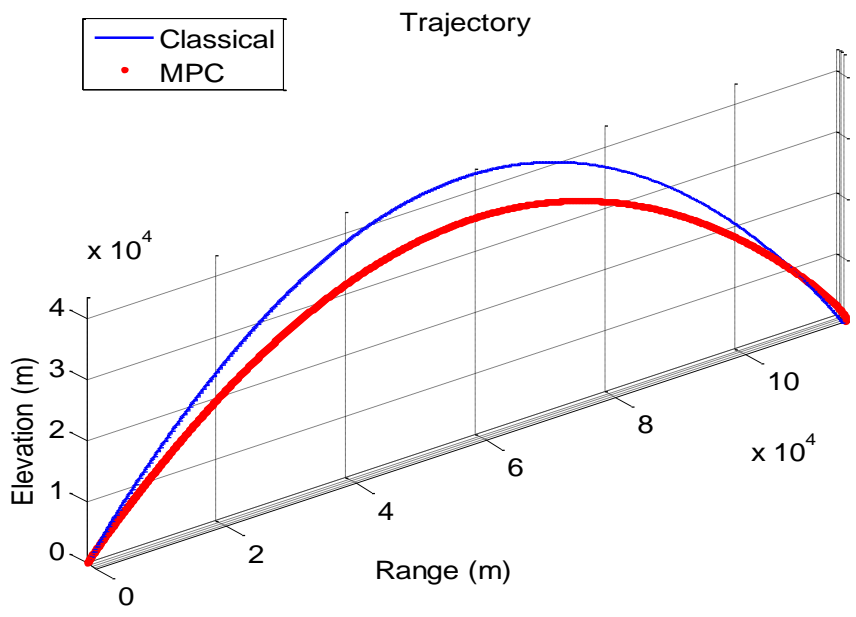

Deviation (m)

(g)

Fig. 9. (Continued) Simulation results

Table 7 Closed loop statistical characteristics of MPC and PID controller

\begin{tabular}{c|c|c|c|c|c}
\hline \hline Controller & Maximum $\mathrm{a}_{\mathrm{n}}$ & Minimum $\mathrm{a}_{\mathrm{n}}$ & Mean $\mathrm{a}_{\mathrm{n}}$ & Standard deviation & $\mathrm{rms}$ \\
\hline MPC & 0.0618 & -0.06 & -0.0001 & 0.0076 & 0.0076 \\
\hline classical & 2.1491 & -1.6047 & 0.0019 & 0.2718 & 0.2718 \\
\hline \hline
\end{tabular}

Table 8 Trajectory characteristics of MPC and PID controller

\begin{tabular}{c|c|c|c}
\hline \hline Controller & Time $[\mathrm{sec}]$ & Summit $[\mathrm{km}]$ & Range $[\mathrm{km}]$ \\
\hline MPC & 180.91 & 36.302 & 115.58 \\
\hline classical & 198.53 & 43.548 & 114.9 \\
\hline \hline
\end{tabular}

The above results were for commanded zero value for normal acceleration, but what about nonzero commanded normal acceleration. This question is answered by Fig. 10.

Fig. 10 shows the response of normal acceleration at various situations:

- In Fig. 10a, the missile undergoes higher dynamics facing wind and noise. Classical controller response is faster than MPC but with M.O. 100\% and does not settle to the required value whereas MPC settles to the commanded value with lower elevator angle. 
- In Fig. 10b, the missile undergoes lower dynamics facing noise only. Both MPC and classical controller responses do not reach the reference values and this is not inefficiency from them, but the normal acceleration requires high angle of attack at low dynamic pressure and in turn requires high elevator angle which can be obtained from control actuator and it is noticed that actuator reaches its saturation point in the classical control whereas the normal acceleration response does not reach the commanded value.

- In Fig. 10c, the missile undergoes higher dynamics as it approaches the surface facing noise only. MPC response does not reach the required value whereas classical control response fluctuates around this value with higher control energy.
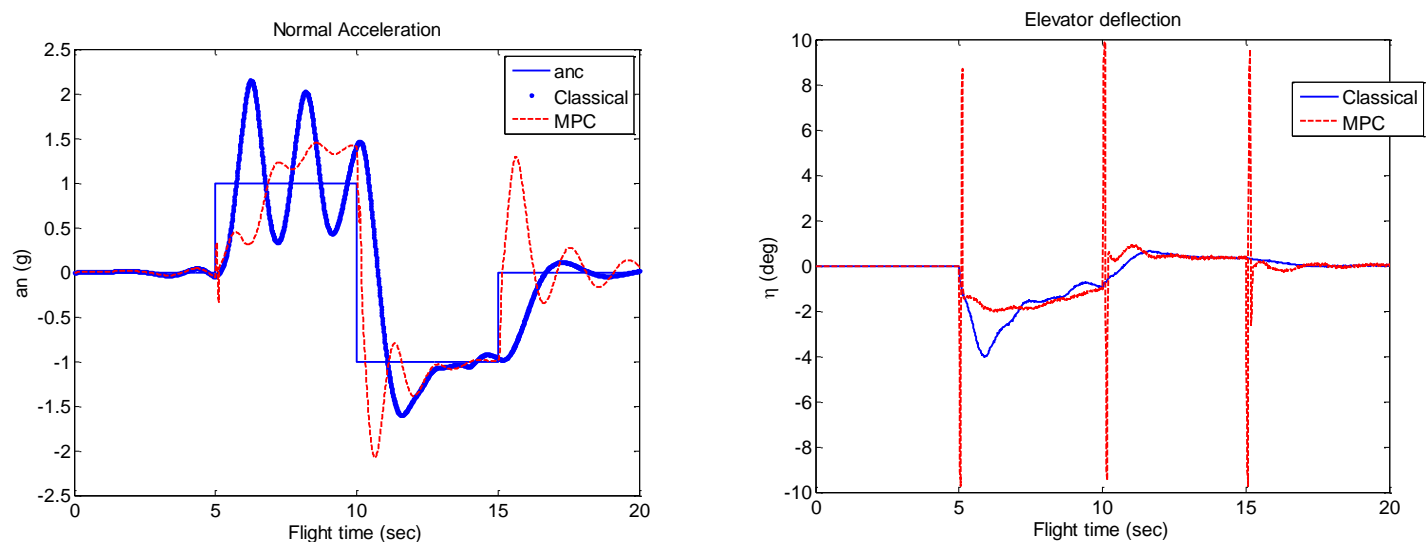

(a)
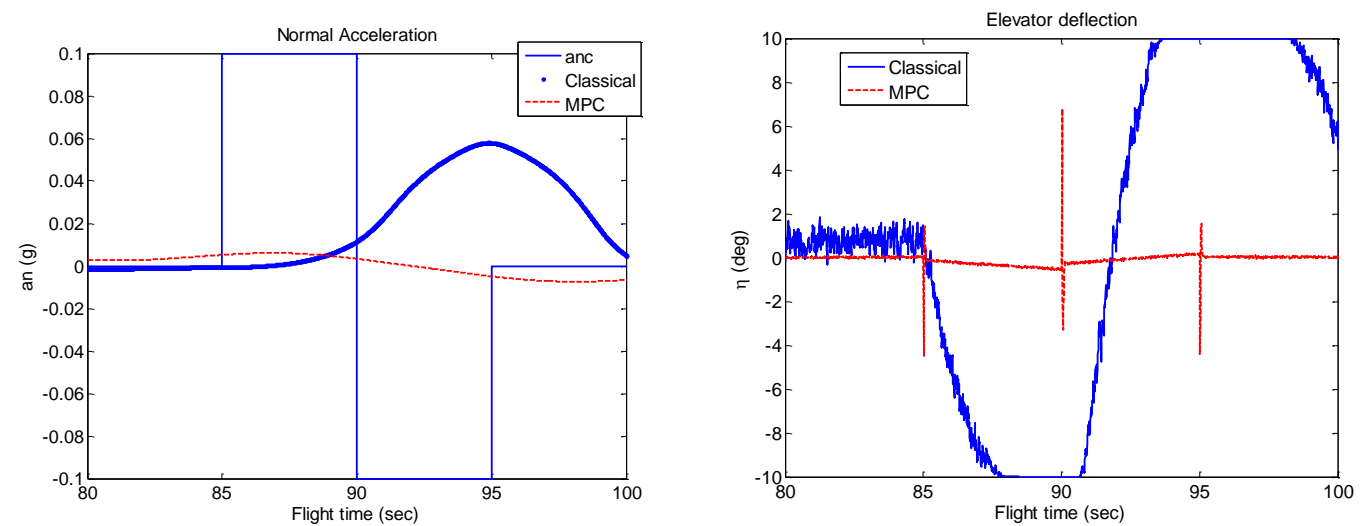

(b)
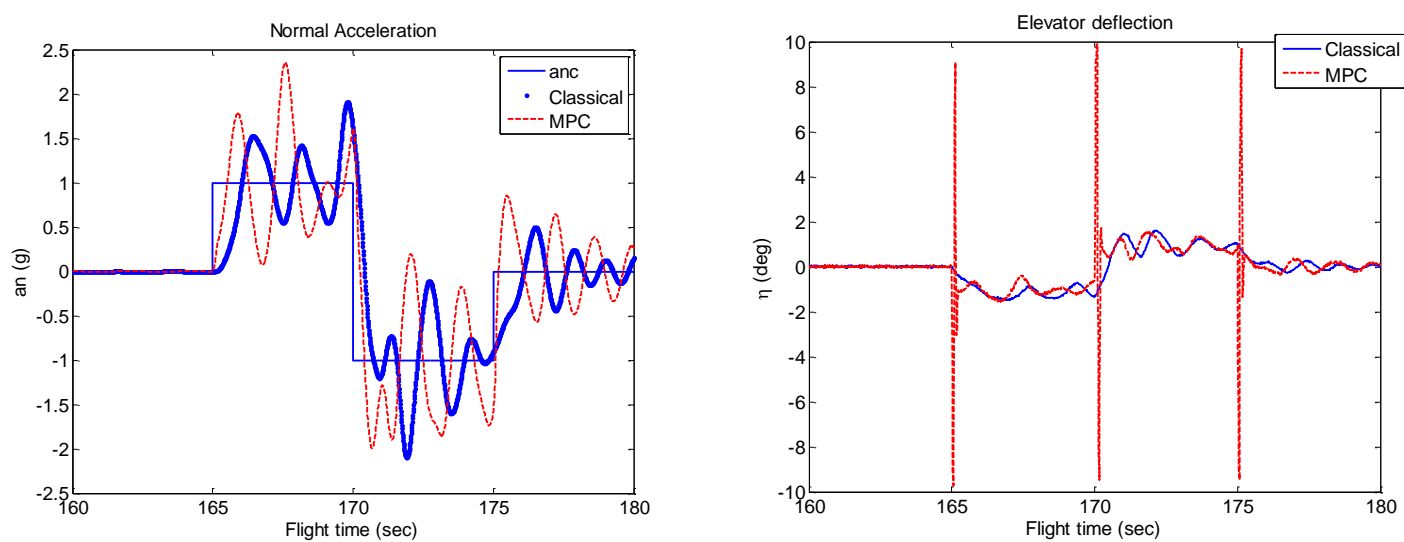

(c)

Fig. 10. Simulation results for specific periods 


\section{Conclusion}

A normal acceleration autopilot for a surface-to-surface missile has been designed using classical and model predictive control techniques. The mathematical model was derived and the aerodynamic coefficients for this model were calculated using Missile Datcom. Autopilot is designed first using classical control theories based on tracking of the command signal of normal acceleration sent from guidance computer utilizing pitch rate and normal acceleration as feedback. Gain scheduling is used to maintain the stability and performance characteristics. Second, the autopilot is designed using predictive control technique. This technique is a digital control strategy that uses a linear discrete model as a plant predictor. The choice of sampling time is based on the sampling theorem utilizing maximum natural frequency of the linearized model. The simulation of both classical and MPC controllers is performed for the whole trajectory in presence of cross wind as a plant disturbance and sensor feedback noise. It is concluded that a single model predictive controller with fixed parameters along the whole flight path has performed like, or even better than, the gain scheduled classical controller designed based on nine operating points. The contribution of this paper stems from applying design techniques (Classical and MPC) to one of the aerospace applications (missile) that is characterized by non-linearity, time-varying, multi-input multi-output and stochastic. These characteristic are justified via the flight path simulation.

\section{References}

[1] John H. Blacklock, "Automatic Control of Aircraft and Missile", 2nd edition, John Wiley \& Sons, Inc., (1991).

[2] Brian L. Stevens, Frank L. Lewis, "Aircraft Control and Simulation", John Wiley \& Sons, Inc., (1992).

[3] William B. Blake," Missile DATCOM, User's Manual -1997 FORTRAN 90 Revision”. AFRL-VA-WP-TR-1998-3009, Feb. (1998).

[4] Farhan A. Faruqi , Thanh Lan Vu," Mathematical Models for a Missile Autopilot Design", Weapons Systems Division,Systems Sciences Laboratory,DSTO-TN0449,(2002).

[5] Benjamin C. Kuo, Farid Golnaraghi, "Automatic Control Systems", 9th ed., John Wiley \& Sons, Inc., (2010).

[6] Alberto Bemporad, Manfred Morari, N. Lawrence Ricker, "Model Predictive Control Toolbox, User's Guide", The MathWorks, Inc., 2012.

[7] Benjamin C. Kuo, "Digital Control Systems", 2nd ed., Saunders college publishing, (1992).

[8] Marc Rauw, "FDC 1.2 - A Simulink Toolbox for Flight Dynamics and Control Analysis", 2nd edition, May 2001.

[9] Peter H. Zipfel," Modeling and Simulation of Aerospace Vehicle Dynamics", 2nd edition, AIAA, Inc., 2007. 